\title{
Collective action and UK wine investment fraud
}

Karina Einarsen

\author{
Lisa Jack* \\ Accounting and Financial Management Group, Business and Finance Faculty, University \\ of Portsmouth, Richmond Building, Portland Street, Portsmouth PO1 3DE UK \\ *Corresponding author: lisa.jack@port.ac.uk
}

\begin{abstract}
Purpose

The purpose of this research note is to examine the measures taken by legitimate wine investment companies and enforcement agencies to counter alternative investment scams.

\section{Design}

We interviewed wine industry and law enforcement specialists to understand the nature of wine investment fraud and the characteristics of the victims. We also drew on secondary data in the form of government agency research and media sources.

\section{Findings}

The majority of wine investment frauds are boiler room operations, using social engineering techniques to draw victims into the fraud. We conclude that countering wine investment fraud requires public education by government, the wine industry and the police.

\section{Research Limitations}

This is a small-scale study that uses interviews with experts in the industry and in law enforcement, and secondary data as evidence. Despite the limitations in the number of interviews, we are able to comment on the social impacts of alternative investment scams and to suggest a theoretical basis for future work in the field. 


\section{Originality}

We outline how collective action theory might be extended to investigate fraud prevention measures in other financial and commodity markets.

Keywords: wine commodity investment, fraud, elder abuse

Paper Classification: Research Paper 


\section{Collective action and UK wine investment fraud}

\section{INTRODUCTION}

The UK's wine market is the sixth largest in the world, with an estimated overall consumption of 133.8 million nine-litre cases per year (Tisi, 2015). Action Fraud, the official UK national reporting centre for fraud and cybercrime, estimates that annually in the UK around $£ 1.2$ billion is lost in scams involving wine and similar alternative commodity investment frauds, with victims involved losing an average of $£ 20,000$ each (Graham, 2016). In August 2017, police arrested three men suspected of wine investment fraud in the UK, and early reports of this case suggested that 39 people lost approximately $£ 1$ million between them (Binkiewicz, 2017). In North America, frauds include that of Premier Cru, a wine investment company in the US, which sold futures contracts for French wine. This is suspected to have been the largest ever Ponzi scheme in the fine wine sector (Frank, 2016), with the company reported to be $\$ 70$ million in debt, though having only $\$ 7$ million in assets in liquidation (ibid.).

We address the issue of professional and public education for this type of fraud. Since 2016, when this study was conducted several legitimate wine firms have started to provide webpages alerting the public to the nature of their business and how to spot fraudulent offerings. They have been encouraged in this by the UK Wine and Spirits Trade Association (WSTA), and some of the findings of this project contribute to WSTA publications. There have also been separate public information consumer programmes on, for example, the BBC. Our study provides evidence to show why this collective action has taken place and the contemporary aspects of wine investment fraud that prompted action. We argue that this activity in fraud prevention 
follows incidents in which vulnerable individuals became involved in investment frauds previously thought to involve only knowledgeable individuals who understood the risks. For instance, elder financial abuse is a growing concern for many governments as it targets a vulnerable group (Malks et al., 2008). We outline how collective action theory, drawn from a micro-sociological perspective on social movements, can help to understand why these counter fraud protections are adopted.

This is a small-scale, qualitative study based on interviews with experts who based on their experience provide a wide-ranging overview. This includes issues faced by the legitimate wine industry and by enforcement agencies in dealing with those who report being defrauded and with the prosecution of known frauds.

In this study, we (1) examine who commit wine investment fraud, and how they operate; (2) categorise potential personality traits targeted by fraudsters. This enables us to evaluate, through the lens of collective action, the counter fraud mechanisms put in place by the wine industry and police, and what lessons arise from other forms of financial crime prevention. As corruption is being tackled internationally as a collective action problem (United Nations Global Compact, 2015), we suggest that public protection against other forms of financial and commodity market fraud could be investigated as social and collective action. Because this is a research note rather than a full, empirical research paper, we conclude by suggesting further research that can be developed from this study. 


\section{BACKGROUND}

According to Anderson, Neglen and Pinilla (2017) in 2014-16, the UK had the world's $10^{\text {th }}$ highest volume of wine consumption per capita (p.5) and the fourth highest share of the world's wine consumption expenditure in 2015 (p.6). It is second in terms of the percentage share of world wine import value for 2014-16 and third in terms of the percentage share of import volume (p.14). As a producer, the UK wine industry is negligible in world trade but imports in fine wines has been evident in Britain since the seventeenth century. All of this contributes to a discourse that the British understand wine.

A sense that wine is a good investment is not misplaced. A 2012 survey found that $28 \%$ of high net worth individuals have a wine collection, and that $2 \%$ of their wealth is tied up in wine (Barclays, 2012 cited in Dimson, Rousseau and Spaenjers (2015)). According to Dimson, Marsh and Staunton (2018), whilst equities and not housing provide the best long-term investment, with an average return since 1899 of $5.2 \%$ based on a world-wide portfolio, wine investments provide the second highest return at $3.7 \%$.

Two other factors contribute to the growth of wine investment fraud in the current environment in the UK. First, there has been a well-document period of austerity following the financial crises of c. 2008. The negative effects of financial stress on markets transmitted from one market to another (for example, the US to the Eurozone) are well documented by Evgenidis and Tsagkanos (2017) and Tsagkanos, Evgenidis and Vartholomatou (2018). Second, in 2015, the British Government allowed pension freedoms that allowed the newly retired to draw down lump sums of cash rather than the previous obligation to invest pension amounts into annuities. Her 
Majesty's Revenue and Customs (HMRC) reported in 2017 that over 1.5 million payments were made using pension freedoms, with 162,000 people accessing $£ 1.56$ billion in just under 3 months at the end of 2016 (HM Treasury, 2017).

Wine investment has increased since 2005, possibly because investors are looking for alternative investments to avoid stock market fluctuations (Mannan, 2013; Holmberg, 2010), including those with money to invest as a result of pension freedoms. Wine investment can be defined as the acquisition of wine for gain, whether as a means for making money or financing consumption or a combination of the two` (Robinson and Harding, 2015, p. 375). The price of high quality wine usually stabilises after some decades and rises when it becomes antique ${ }^{\mathrm{i}}$ (Dimson et al., 2015). ${ }^{\text {ii }}$ Legal wine investment is similar to investments in precious stones or art (ibid.), but certain investment cases, some involving wine experts such as Spyros Constantinos (Budd, 2015), Loïc Pasquet (Anson, 2016), Rudy Kurniawan (Mercer, 2015) and Daniel Snelling (Budd, 2013) show that this type of fine wine investment is subject to fraud.

There is a tradition of deceit in wine selling (Daab, 2011). Manipulation involves the bottle and its design being forged, or the wine itself being mixed or 'stretched', with the intention to sell it as a more expensive wine. Lecat et al. (2017, p. 84) provide an inventory of forgery techniques employed in France, noting that:

As the traceability of great wines is becoming crucial, a new type of relationships [sic] between producers anxious to offer genuine estate wines and consumers anxious to drink 
the bottles they ordered has developed. This new constraint became a marketing opportunity for producers.

Forgery techniques in Lecat et eal (2007) include usurpation of brand identity/awareness, for example by taking the name, design or symbols from a premium brand and applying it to an inferior one. The use of very similar bottles and labels (rather than forged ones) are also used to 'pass off' wines. Another technique is to acquire empty bottles from a premium brand and refill them with a lessor or counterfeit wine. Some restaurants have apparently been known to smash finished bottles to prevent this fraud. Nauth (1977, translated by Holmberg, 2010) earlier also identified chain of bills frauds, where a shipment of low-quality wine is bought by (1), who pays cash, and resells it to (2), for a little more than it is worth. (2) increases the price a little more when reselling it to (3). (3) places it on the market for everyone to buy. All three are party to the fraud, as they are aware that the wines is being passed off. However, the stage enhancement in quality and price, makes investigating the fraud more complicated.

Counterfeiting incidents have made vintners more protective of their newly produced wine. They add specific markings or other characteristics to the bottle to make it difficult to copy, although this only affects contemporary wines, not investment in old wine (Daab, 2011).

Wine investment fraud is different to the manipulation of wine products. There is no 'typical fraud', and a variety of methods and inducements are used (Langenderfer and Shimp, 2001). Legitimate direct investment in wine involves purchase of bottles of wine in either primary or secondary markets (Aytaç et al., 2016). The primary market involves purchase of bottles directly 
from wineries "en primeur" - before it is bottled and released onto the market, and investors look to lock-in the price of wine prior to bottling (Coffman and Nance, 2009). Secondary market investments involve purchase of wine bottles through auctions or known wine merchants (Aytaç et al., 2016). Bottles are registered and stored in bonded warehouses until sold. Indirect investment in wine are achieved through wine investment funds, where, like traditional mutual funds, each fund has a different portfolio, containing several types of wines, in which one can invest (Aytaç et al., 2016). This create the perfect scenario for fraudsters as they can claim payments up front. The wine bottles are not expected to be physically delivered to the investors and it can take years before the fraud is discovered (Wall, 2011). The industry is also highly vulnerable to Ponzi schemes, as there are no dividends or other expected regular returns: investors are simply waiting for the wine to increase in value (Ganesh, 2016).

Investment fraud may be defined as 'any fraud that is related to stocks, bonds, commodities, limited partnerships, real estate, or other types of investments`, often built upon deceitful promises and agreements, where targets are persuaded or coerced into making an investment (Albrecht et al., 2014, p. 557). The FBI (2018) lists 23 “common fraud schemes" on their website, of which some could be utilised for wine investment fraud, including advance fee schemes, internet action fraud, internet fraud, investment fraud, Ponzi schemes and telemarketing fraud (boiler room fraud).

Social engineering can be defined as the "exploitation of humans in order to gain unauthorised access to sensitive information" (Mouton et al., 2014, p. 266). It can exploit psychological biases and limitations. For instance, an individual may base his/her investment choices on a 'gut 
feeling` about the person they are talking to, or the nature of the offer, and overlook the risk that they may lose their investment. According to Kahneman and Tversky (1973), this gut feeling, or intuitive prediction, is based on a heuristic termed representativeness. A decision is grounded on what is to the victim most representative of a good investment from the evidence at hand. If individuals' heuristic measurements are based on non-relevant stored information, they can be misled in judging the legitimacy of investment opportunities. The optimal decision-making needed may exceed the investor's processing capabilities, and therefore available heuristics are the quickest solution (Bosley et al., 2018; Payne et al., 1988). Humans are adaptive and their actions and behaviour is malleable (Simon, 1990), thus, some might be victimised due to the manipulation of their gut feeling, whilst others might fall victim due to other factors, such as a propensity to take risks (Van Wyk and Benson, 1997).

Fraudsters violate trust, often avoid confrontations, and are not necessarily prohibited by national borders due to technological devices (Shover et al., 2003). A common method for wine investment fraud is boiler room cold-calling (Button et al., 2014; Mannan, 2013; Levi, 2008; Stevenson, 1998). There is rather little literature on the victims of investment fraud and on victims of financial crime in general. Button et al. (2014) offer an in-depth study interviewing UK victims of fraud, which challenges the perception that fraud is victimless. In many cases, victims and families are financially, mentally and physically damaged for years after the crime. The Financial Conduct Authority (FCA) in the UK investigated victim profiles in cases of investment fraud, including alternative investment frauds involving fine wines. Graham (2014), who conducted the quantitative study in that FCA project, found that the most likely victims are the 'retired with resources' and the 'mature and savvy'. However, Harvey et al. (2014), who 
carried out the qualitative partner study for the FCA, found that there were an increasing number of victims who had acquired resources in retirement who were not at all 'savvy' in terms of investment, losing significant sums (an average of $£ 20,000$ ) to investment fraudsters.

Growing concern about elder abuse involving finance is evident in several countries and grew into a significant discourse in the UK from around 2015, although concerns have been raised for many years (van Bavel et al., 2010; Malks et al., 2008). The Securities and Exchange Commission in the US has issued several initiatives (see for example Fleming, 2015) and the Department of Justice commissioned the Elder Abuse Guide for Law Enforcement (EAGLE) ${ }^{\mathrm{iii}}$. Here, financial elder abuse is explained as "using an older adult's money or assets (pension, home, social security checks), contrary to their wishes, needs or best interests, or for the abuser's personal gain"iv . Further, the FCA (2016) informs that more than $25 \%$ of those over 55 years old in the UK are defrauded by an unauthorized firm selling unregulated products such as wine.

\section{Conceptual framework}

Rather than model the processes at play in the fraud, we are interested in the what would mobilise different social actors to engage in collective action to prevent the fraud. The motivation to look at this is grounded in the fact that the UN and others are applying the principles of collective action theory to tackle issues of corruption across the world (United Nations Global Compact, 2014). They suggest that by mobilising industry, enforcement agencies and civil and regulatory bodies to work together, corruption might be eradicated, or at least contained, in those countries most affected. This study shows a movement towards collective 
action to tackle the issue of wine investment fraud, which appears to have been stimulated by the need to prevent elder abuse. Whilst the problem exists in many countries, the UK's response appears to be the most developed within this industry.

Collective action concerns the motivation of different groups and individuals to work together to enhance their status and achieve a common objective. Collective action theory has two strands. The first is a rational choice, game theory approach with roots in institutional economics, derived from the work of Mancur Olson (1965). Researchers are primarily concerned with ascertaining optimal group sizes to achieve outcomes in the form of public goods, and with the problem of free riding on the actions of others. Ostrom (2009, p. 195) notes that 'many theorists interested in collective action focus on the potential positive effects of participants adopting simple heuristics to use when they are in a social dilemma situation' and on the norms that groups develop to address situations. The second, more sociological strand looks at the micro-level origins of social movements and more contentious collective actions, such as terrorism (Oberschall, 2004; Pinard, 2011). Such work tends to be transdisciplinary, drawing on, for example, psychology, anthropology and politics. There are several conceptual frameworks and qualitative methodologies available, but we focus on frameworks that identify people's motivations for engaging in collective action.

Oberschall (2004) identified four dimensions of collective action to explain motivation to engage in terrorism, although the model was developed for more benign social movements. The four dimensions are discontent, ideology-feeding grievances, capacity to organise, and political opportunity. Similarly, Van Zomeren et al. (2008) use injustice, efficacy and social identity 
Pinard (2011) takes the analysis further and finds that discontent and injustice are insufficient as descriptors of motivation. Whilst some form of grievance may act as a catalyst, aspiration and moral obligation also provide impetus to collective action. Pinard (2011) then examines collective incentives and collective identity as necessary elements, whilst also examining capacity and political expediency. In the discussion section of this paper, an outline of how the four dimensions might apply to collective action against wine investment fraud is provided. Given the limitations in the data, the analysis is constrained, but it does indicate that there is scope for theories of collective action to be applied beyond the study of the prevention of corruption in financial crime.

\section{RESEARCH METHODS}

The research design is based on semi-structured interviews, using purposive sampling. Various specialists and professionals, either directly or indirectly linked to the wine industry in Europe, were identified through discussions with a representative of the UK WSTA. The overall number of potential expert interviewees is small - around 20 individuals in the UK - and our sample has seven experts. Whilst Marshall et al. (2013) recommend a minimum sample size of 15 interviews for a full study, Crouch and McKenzie (2006) and Bogner et al. (2014) recognise that for smaller, more reflective studies involving experts, even smaller samples might be acceptable, depending on the nature of the data being obtained. Each participant was accepted with diversity of experience and points of view in mind (see Table 3). 
The interviews were recorded using a digital audio recorder, which produced about 11 hours (see Table 1) of recordings. The interviews were transcribed by the researchers, anonymised and stored securely.

\section{INSERT TABLE 1 AROUND HERE}

Subjects applied their experiences to broader social contexts and reflected upon aspects of the "reality" of the industry, and its limitations (Braun and Clarke, 2006). Then a thematic analysis of the interviews was undertaken. After close reading of the transcripts, the themes and codes were analysed using the following scheme. These themes emerged in part from the semistructured interview design developed from the literature, and in part from identifying patterns in the responses of the interviewees when they expanded on their experiences in encountering victims of such fraud:

1. Development of wine investment fraud.

- Why wine?

- Counterfeit wine versus overpriced or non-existent wine.

2. Wine investment fraud strategy.

- Cold-calling.

3. Characteristics of (wine investment) fraudsters.

- Social engineering. 
4. Characteristics of victims.

- Lack of due-diligence.

- Lack of knowledge about the trade (wine investment).

\section{Prosecution Process.}

- Misrepresentation.

- Rip \& tear.

6. Unregulated versus regulated wine market.

7. How is the industry affected by wine investment fraud?

8. Mitigating wine investment fraud.

The different data extracts have been cross-analysed to identify relational patterns, to produce the clearest thematic analysis possible. The coding identifying the themes has been conducted from a "top down" approach, compared to the more data driven inductive approach (Braun and Clarke, 2006). Some of the identified themes are descriptive (semantic), mainly focusing on the "what" and "how", while others are broader themes (latent), considering the "why".

A constraint was a restriction of ethical approval based on the inexperience of the main interviewers: they were not granted permission to carry out interviews with victims or convicted 
persons that might have been useful to provide a more complete analysis However, an experienced researcher worked with the interviewers to ensure that the analysis was performed robustly. Despite this, the project has value because of the expertise of the informants (Bogner $e t$ $a l ., 2009)$ and the fact that we could draw on high value secondary data in the form of empirical research studies with victims of investment frauds, and on reputable media sources, such as Harvey et al. (2014) and Graham (2014). Finally, the ability to triangulate our qualitative findings against a conceptual framework of collective action, provides some preliminary level of confidence and validity in our conclusions.

\section{FINDINGS}

We grouped our findings into four overarching themes: the nature of prevalence of wine investment fraud in the UK, the type of fraudster involved and how they operate, the nature of the victims (from the perspective of our expert interviewees), and the response of the industry.

The nature and prevalence of wine investment fraud in the UK in 2016

Some of the interviewees commented that wine investment fraud has increased in recent years and INT.C offered this explanation:

“...when the price of Bordeaux went up significantly circa 2005, and the En Primeur...combined with China as a significant market...coupled with the financial crisis of 2008 when people were 
looking for an alternative investment, it has sincerely been a significant growth since that".

The interviewees emphasised throughout that wine investment fraud does not necessarily differ in operation from other types of alternative investment frauds, for example in diamonds or carbon credit. However, it is an easier proposition for victims to identify with wine as an investment. As INT.C points out:

"Wine at the high end has a sexy image: Bordeaux, Chateau, does have a sexy, luxurious image to it, and that is part of its attraction".

More specifically, INT.E said that:

"Traditional wine investment tends to happen, you buy En Primeur, the wine comes in, you get small movements, incremental movements, over a very long period, with the idea that after twenty years, you bought two cases, and you are going to sell one, and that one has paid for the first case".

Any other type of investment in wine being offered is likely to be fraudulent, in their view. The main problems were perceived to involve counterfeit wines, and over-priced or non-existent wines. The latter are most prevalent in boiler room frauds. As INT.C explains: 
"On the whole, people getting caught up in [counterfeiting] are wealthy wine lovers, who go to auctions, [and I suspect]... are highly unlikely to fall for investment scams, the type that I am talking about... The wine investment [fraud] I'm talking about is largely someone phoning you up and saying look I can offer you this case of Lafitte, that is going to make a profit".

In practice, these fraudsters would find it difficult to deal in actual bottles of wine. To get counterfeit or other bottles into a bonded warehouse (where many legitimate investment wines are stored), they would encounter background checks and exhaustive authentication processes.

\section{Cold calling method}

INT.C explained the attraction of cold calling to fraudsters:

"It's easier to get your brokers to phone up people. Why would you go through the trouble of counterfeiting...making your counterfeits look pretty genuine. Why bother...Sell these cases at twice the market value. Much easier. Either selling non-existent wine or selling existent wine at exaggerated prices with exaggerated promises".

Overall, the interviewees collectively identified four main strategies:

- Selling non-existent wine as investment 
- Selling wine investments at inflated prices

- Selling wine at low prices and charging high trader commissions

- Luring people to sell their wine, making them deliver wine prior to payment, then failing to pay.

INT.A explained that:

“...They're virtually all the same...classic boiler room methods of selling, very high pressure sales techniques are employed by very well trained salespeople, which...usually rely on cold-calling....and they work by calling on people's greedy nature I suppose... If you're naïve enough you fall into the trap of seeing the money, and not seeing that something is too good to be true".

INT.D offered a description of other strategies:

"...Another example is to sell the customer a fair price but to charge them a very high commission for their service, that after all the trades the capital gained has been eroded by the commissions. Another strategy is where people with wine are contacted and are offered very 
high rates for the wine, get the wine delivered but never really pay for the wine that was delivered to them".

Most argued that the strategy has not developed much over time; the fraudsters have lists, an office operation, and people cold-calling. A front may be added to the fraud, through credible looking websites and brochures, a registered office within the 'square mile' in London, and a false name that may resemble legitimate company names (Forward, 2015).

The interviewees stated clearly that legitimate wine investment companies do not need to cold-

call customers, as customers approach them. However, they do send offers to people who have signed up for their newsletter, or telephone them if they are a member of their services. From a wine broker's point of view:

“We don't cold-call...That's why we work hard on our reputation and branding...These fraudsters usually cold-call people who are not generally wine buyers and do not have any product knowledge around wine". (INT.E)

\section{Characteristics of fraudsters in wine investment}

Other interviewees felt that there were wine investment fraudsters with a particular interest in wine, although INT.C argued: 
“...they are first and foremost fraudsters, rather than wine investment fraudsters".

INT.A claims that those running the frauds look for specific types of people to perpetrate them. The recruits are highly focused on earning money quickly, being enticed into this lifestyle, which can only be supported by a certain income:

"I think they are extraordinarily good salespeople. There's no doubt that they're sales trained, you know the people who do this properly, say for a living, the people who make a lot of money out of this, take a huge amount of care to train their staff, and they are brutal in terms of the people they will or won't accept...".

Summed up, the interviewees described the fraudsters as being intelligent, getting a buzz out of the trickery, and believing the story they sell. They also perceived fraudsters as having a high level of criminal intent, low ethical sensibility, and an ability to put their desire to earn ahead of the losses of the victims. Several interviewees felt that the fraudsters were above all 'extraordinarily good sales people', and the INT.F1 and INT.F2 found them to be pleasant and empathic. INT.C stated:

"A fraudster who is good at their job would seek to build empathy with the person they are defrauding... Seeking to persuade you [that] 
"wine is a safe harbour, not affected by economic trends" et cetera.

Which of course is nonsense".

According to the investigators interviewed, a central element of social engineering is knowing your victim and 'playing the right cards`. The fraudsters are skilled at social engineering and their skills are polished through practice as cold-callers. When asked particularly about the method used, INT.A explains that there is a definite pattern:

“...high-pressure sales techniques that involve cold calling and then repeated calling thereafter. They bamboozle the customers with extraordinary facts, which may not be true and the victims do not see that some of these facts are too good to be true".

Boiler room fraud has another attraction for scammers: it is easy to move location, as all the fraudster needs is a telephone. INT.A commented:

“...When not arrested...they set themselves up with a new environment, new serviced office, somewhere in the same area...It is extremely hard for the authorities to curtail it...".

The victims of wine investment fraud 
When talking about victims of wine investment fraud, interviewees mentioned lack of awareness and lack of due diligence prior to the investment. They suggest that targets may be elderly and/or suffer from disabilities, creating a more complex social problem.

INT.F2:

"... Some of the elderly are that lonely that they are happy to speak to these people on the telephone...".

The cold-callers allegedly also target those with reduced mental capacity, as suggested in the statement of INT.C:

“...unfortunately there is a number of instances where the person has dementia or Alzheimer's. And that is played on by the broker's or the company...I think quite often people label these [victims] as being greedy. I'm not convinced that that is entirely fair. I think it can be fair if somebody is a sophisticated investor and has full control over his mental faculties...”.

However, INT.A argues that anyone can fall victim to these scams:

"I had a guy phone up who...worked in high profile banking, all his life...He put a quarter of a million pounds into this wine investment company who gone, just disappeared, with his money...A week later, 
I had a phone call...And he was a former head within a UK Police department...He'd taken out a lump sum of the pension, and he put half of it into this investment company, who got him really excited, and he said, 'I can't believe I've done it' “.

Several interviewees raised the issue that the elderly and those with mental disabilities may not be able to carry out due diligence, whilst other victims had not carried out such precaution and fell victim to the fraudsters' social engineering skills. Greed and a penchant for risk-taking may also be factors. All those interviewed were strongly of the opinion that victims of this type of fraud do not have knowledge about wine investment.

Based on both primary and secondary information, this study identifies three main types of victims summarised in Table 3.

INSERT TABLE 2 AROUND HERE

This study found that there are several reasons why people fall victim to wine investment fraud, and the impression is that the fraudster knows how to exploit their weaknesses. The main exploitable traits found were: general human error, mental challenges, lack of knowledge about the trade and due diligence, trust, loneliness, greed, risk-seeking and wealth. 
There is secondary data about the victims of investment fraud from the UK in the form of a two stage research carried out by and on behalf of the FCA, which regulates banking and investment activity. This is one of the very few studies to examine the victims of alternative investment fraud rather than the fraudsters (Harvey et al., 2014; Graham, 2014). The aim of the FCA through the project is to disrupt investment fraud at an earlier stage than tends to happen at present, as "the FCA receives 5,000 calls a year about suspected investment frauds. $20 \%$ of the investors had already paid money to fraudsters; it takes an average of four calls before people contact the FCA" (Graham, 2014, p. 2). The quantitative study carried out by the FCA (Graham, 2014) looked at victim profiles in over 11,000 cases of investment fraud, including fine wine fraud, and found that "victims tended to be wealthy, financially sophisticated males, with an escalating correlation to older ages. There was particularly strong representation from residents of the South or East of England, and from either very urban or very rural locations.” (ibid.) This was particularly the case for boiler room frauds. They fit with the 'elderly' category that we identified. The report identifies that younger persons with fewer resources are more likely to fall for 'get rich quick' scams labelled as 'other investment frauds' but it is not clear that this means wine investment fraud, which is most commonly a boiler room fraud. However, the profile of younger victims would fit into the 'other' category here.

The qualitative study by Harvey et al. (2014) included a sample of 31 victims, the majority of whom were male and over the age of 50. Seven were victims of alternative investment fraud. The case studies and victim stories confirm our interviewees' comments about how the fraudsters operate using social engineering techniques. However, elderly victims with mental health issues were not included. It is surprising that that our commentators appear to have been touched by the 
crimes on the vulnerable elderly, through dealing with these victims first hand, or having had the stories related to them. They may also feel empathy for the elderly who have resources from retirement perhaps but are not otherwise particularly affluent. Harvey et al. (2014) found that many of their interviewees were new to investing, having acquired a substantial sum of money (by their living standards) through retirement, inheritance, sale of a business or insurance. It is not too difficult for fraudsters to identify and target the bereaved, retired or recipients of a financial gain. What is interesting is whether the outrage or empathy expressed by our interviewees in the wine industry and enforcement agencies would be sufficient to motivate action on behalf of the wine industry, as well as the police and FCA.

\section{Tackling the problem}

In 2016 when the data was collected, there was a reluctance among the legitimate wine investment businesses to get involved with prevention of wine investment frauds. They were clear that they were operating legitimately, and with knowledgeable investors. Despite awareness and knowledge of wine investment fraud, they felt it was the job of the police and other enforcement agencies to deal with the problem. They felt that their clients would not be exposed to the fraud because

"It is rare for somebody to fall victim, who knows about...or buys fine wine. All too often it is somebody who knows very little about wine, they might buy wine from the supermarket... They are playing on people being ignorant, or not very knowledgeable, about the product they are being persuaded into invest in" (INT.C). 
This argument is expanded on by INT.E who states:

"First of all, wine investment is not suitable for most people...Second of all, because it is so illiquid, it's not a good investment tool. You have to...not only know the price you should be paying, and by that you should be calling around all the merchants, you should also know what's the supply of that wine, what's the distribution of that wine...Wine investment is not suitable for people who do not know wine at this level".

He illustrates this point by comparing wine investment to investing in horses. Wine is something people feel that they know about, as they might drink it every week:

“...Just because you're riding a horse doesn't mean you know how to invest in a horse, and if you're drinking wine, you may not know how you should invest in wine... So it is a lack of knowledge".

There were divided opinions about the extent to which it is easy for the public to access sufficient information to be able to understand wine investment. Some gave websites such as winesearcher.com and the well-known merchants' websites as examples of information including prices that are accessible to everyone. However, that does not necessarily make wine investment understandable INT.E argues: 
"I can tell you pricing. But what will that show? Doesn't show you what the demand is. Doesn't show you what the supply is. You can get the supply, but you don't know how it's been distributed, which has a huge effect on any of the supply at any given time".

This study identifies four enablers of fraudulent activity within the UK wine industry:

- The wine industry is not affected by the fraud, other than in a purely reputational manner, and possibly by loss of sale.

- The industry is an unregulated industry, running in a free market in the UK.

- It is a traditional industry, which to some extent is built on trust and relationships.

- Wine as an investment product will often stay in bonded warehouses

However, since we completed the study, several of these firms have now issued advice against wine investment frauds on their websites (see for example, Majestic Wine PLC) ${ }^{\mathrm{v}}$, and appear to be more actively engaged in public education, alongside their trade association and the enforcement agencies.

\section{DISCUSSION}


The findings show that the perceptions of a sample of industry stakeholders are that the majority of wine investment frauds are boiler room operations that use cold-calling and tactics associated with social engineering. These are manipulative situations in which the fraudster demonstrates that they can meet their targets' needs for investment. Interviewees also gave evidence of what is termed 'continuous social engineering', where the scam extends beyond calling to the use of, for instance, free wine, and a legitimate-looking website.

Those interviewees who work within the wine industry argued that they are not affected by frauds other than in a purely reputational manner, and from potential loss of sales. The wine industry is an unregulated industry ${ }^{\mathrm{vi}}$ in a free market, operating on a global level, with a product about which most people have little knowledge. Furthermore, wine as a product of investment will often stay in bonded warehouses. Arguably, these are enabling factors, as the fraudsters operate outside the industry and those within the industry can distance themselves from fraud prevention, citing that it is a generic social problem, rather than one for the industry.

Hines (2001) found that a collective effort of authorities, the wine sector and private investors, taking several measures together, could minimise wine fraud. However, he was focused largely on substitution and other physical manipulations of wine products. Those industry insiders sampled in 2016 for this study regarded wine investment fraud as an external problem, one for law enforcement agencies. The question is: what would it take for the industry to take action to mitigate cold-calling fraud, through awareness of wine investment fraud, communication, and transparency, and by questioning operational processes and internal controls? 
From 2017 onwards, several firms and agencies have been publishing details of how the wine investment industry really works, and how to avoid frauds. This coincides with several actions on elderly financial abuse by government agencies in the UK, the USA and elsewhere. We postulate that the collective action taken very recently is motivated by the realisation of the extent to which the victims of the crime are, largely, elderly.

The policeman and the judge given as examples in our findings probably fell victim due to general human bias exemplified through heuristics, for instance, availability (Kahneman and Tversky, 1973; Tversky and Kahneman, 1973). Victims being socially engineered could possibly experience this manipulation of biases even more, as the circumstances and benchmarks used to make judgments are consciously manipulated by the fraudster. Some are targeted because they are individuals looking for ways to ensure future financial security during or after their retirement, as supported by Lokanan`s (2014) study. A factor enabling the growth of the fraud in UK was the government's decision in 2014 to allow pensioners to draw down part of their pension early, rather than invest in an annuity, which was the previous legal requirement.

The group that caused the main concernto our interviewees though was people with mental disabilities, such as Alzheimer's or dementia. All our interviewees saw these as one of the main targets for investment frauds, although they were unable to go into specific details about the transactions taking place either due to confidentiality or the general nature of their knowledge. There is a risk of bias in the comments, because participants may have particularly noticed these victim stories, and given them more weight than others. 
In the last few years, elder abuse has become a priority for government and other agencies. There are public awareness campaigns in several countries, including the USA. Alongside this, the FCA in the UK, and other similar agencies such as the FBI in the US, are trying to ensure that the elderly and others are not enticed by alternative investment frauds (Harvey et al., 2014; Graham, 2014). These are also recognised as an issue for professionals, one white collar crime prosecutor in the USA identifying that "the trusted advisor has an indispensable role in protecting investors not only as they plan for retirement, but particularly as they begin to face the special challenges and dangers of diminished capacity" (Fleming, 2015). There has been recognition of elder financial abuse in North America for over a decade, and several schemes have been designed to help counter such abuse (see for example Malks et al., 2008).

What is important for our story of wine investment fraud is that this background discourse has begun to mobilise the wine industry into protecting itself. In other words, the barriers we identify in Table 6 as reasons for the industry distancing itself from responsibility for action have been to some extent overridden. The actions taken recently by the wine industry take the form of public education about the previously esoteric and exclusive world of legitimate wine investment, and how legitimate businesses would and would not act. We can infer that the risk of being associated with wine investment frauds and abuse of the elderly in particular has led to collective action from police, government agencies, trade associations and the legitimate wine businesses, using traditional and social media as a counter fraud measure. The extent to which the industry is acting in self-interest, rather than through altruism, is difficult to assess. However, a further project is at the time of writing being conducted by colleagues to assess the motivations for the counter fraud measures put in place by the wine investment industry as a response. 
Using the dimensions of collective action proposed by Pinard (2011) and others, outlined previously, we can infer that outrage provided impetus for industry actors to join with police and other agencies in collective action. In theoretical terms, discontent with the fraudsters tainting the industry (Oberschall, 2004), or the injustice of being implicated in the activity (van Zomeren et al., 2008), or a sense of moral obligation (Pinard, 2011), could all create motivation. The capacity to organise and a belief that there would be some efficacy in doing so is, especially through the use of social media, websites, radio and television airtime, and press releases,. There appears to be a consolidation of social identity as the 'legitimate' investment trade against the fraudsters and a sense of political opportunism and self-worth in countering a social evil in the form of elder abuse.

Another discovery is that some of the victims do not seem to be able to protect themselves if targeted. Increasing security awareness, and coaching and training to enhance knowledge and awareness, are suggested proactive measures to avoid victimisation (see for example, Lokanan, 2014; Drew and Cross, 2013). However, Alves and Wilson (2008) argue that educating those targeted by fraudsters may not be effective and argue that prevention should focus on education and training to encourage people to report boiler room frauds, in order to fight what they label as 'financial abuse of the elderly'. This method alone may not be sufficient to prevent its occurrence, although Graham (2014) reports that fewer people are paying money to fraudsters before calling the authorities (20\% in 2014 compared with $60 \%$ in around 2010). The efficacy of collective action (van Zomeren et al., 2009) for public awareness needs assessing in further work in the form of empirical research. 
The theoretical frameworks for the motivations behind collective action offered by Pinard (2011), van Zomeren et al. (2008) and Oberschall (2004), and others, could be explored in greater depth, and a more robust conceptual approach developed for the context of financial crime. More work is needed to understand the extent to which existence of elder abuse in relation to wine investment fraud is the key motivation for collective action. Graham (2014) found that victims of wine investment fraud are most likely to be the retired with resources who are also 'mature and savvy'. Intuitively, there is less likely to be sympathy with the less infirm elderly who make mistakes.Bosley et al. (2018) found something similar in pyramid scheme frauds, finding a correlation in:

"victimization beyond cognitive ability, including impulsivity, risk preferences, religiosity, and prior exposure to pyramid scheme fraud. Subject reliance on probabilities in decision-making and the accuracy of subjective expectations are the most statistically significant predictors of the decision to invest..." (see Harvey et al. 2014).

Another inference may be that the legitimate wine investment companies would like retirees surplus resources to be invested with them rather than with fraudsters, though the interviews with experts from wine businessesuggest that they are motivated to protect the reputation of their own trade.

Nearly all the available papers on the subject of collective action in financial crime professional as well as academic - discuss actions against corruption by local and national 
groups. We suggest that theoretical frameworks of collective action (economic and sociological) could be used by researchers in forensic accounting and counter fraud to investigate other areas of interest. The first area might involve qualitative research into movements (or lack of social movement) against fraud by companies. In the literature, fraud prevention is often only discussed in terms of the fraud triangle and improved internal controls by individual companies to protect against employee fraud. However, alternative investment scams, company financial statement frauds, and the sub-prime mortgage scandals that contributed to the 2008-9 financial crises are systemic, social problems. These cannot be adequately explained by the fraud triangle or internal control deficits. The second area might involve researching why certain social groups get drawn into frauds or financial crime. Baker and Faulkner (2003) examine the diffusion of fraud through social networks, and Granovetter's (1985) work on embeddedness and the role of social networks in corrupt communities is a useful starting point for such research. There is also potential to look at the issue from the angle of group optimisation and free riding, following Olson (1965) and others using quantitative game theory methods. In wine investment fraud, there is scope for a much deeper analysis of benefits for the fraudster, the opportunities for realising these, and the persistence of the fraud, from both quantitative and qualitative research standpoints.

\section{Conclusion}

We examined wine investment fraud in the UK through the experiences and perceptions of a purposeful sample of experts with oversight of the field. The interviews allowed us to gain an 
understanding of how wine investment fraud is perpetrated and of the nature of the victims of the fraud.

This study is presented as a research note to recognise the constraints of the available data and the inferences it is possible to draw from that data. Our theoretical analysis is explanatory and based on existing frameworks. The study offers two contributions. First, the expert interviews present information about a particular type of fraud drawn from extensive experience and identify in part what motivated the wine industry in the UK collectively to put in place counterfraud measures. Second, we identify collective action theory as an alternative framework for the analysis of counter fraud initiatives by social groups, taking such theory beyond the problem of corruption and into the field of financial crimes in capital and commodity markets. The Financial Conduct Authority's work in this field (Graham, 2014; Harvey et al, 2014) could be supported further by the evidence from our study. Regulators and investment advisors need to be part of the ongoing collective action to educate potential investors and their networks of family and friends about the legitimate wine investment trade and the need to avoid online investment scams.

\section{ACKNOWLEDGEMENTS}

We would like to acknowledge the support of David Richardson and the Wine and Spirits Trade Association for providing a bursary to cover the travel costs involved in this project.

\section{REFERENCES}

Albrecht, W.S., Albrecht, C. O., Albrecht, C. C. and Zimbelman, M. F. (2014), Fraud Examination. Cengage Learning, Boston, USA. 
Alves, L. M. and Wilson, S. R. (2008), "The effects of loneliness on telemarketing fraud vulnerability among older adults", Journal of Elder Abuse \& Neglect, Vol. 20 No. 1, pp. 63-85.

Anderson, K, Nelgen, S, and Pinilla, V (2017). Global wine markets, 1860 to 2016: a statistical compendium. University of Adelaide Press, Adelaide. DOI: https://doi.org/10.20851/global-wine-markets. License: CC-BY 4.0

Anson, J. (2016), “Bordeaux Liber Pater winemaker found guilty of fraud”, Decanter, 17 January, available at: https://www.decanter.com/wine-news/bordeaux-liber-paterwinemaker-found-guilty-of-fraud\%E2\%80\%A (accessed 17 August 2017).

Aytaç, B., Hoang, T. H. and Mandou, C. (2016), "Wine: To drink or invest in? A study of wine as an investment asset in French portfolios", Research in International Business and Finance, Vol. 36, pp. 591-614.

Baker, W.E. and Faulkner, R.R. (2003), "Diffusion of Crime: Intermediate economic crime and investor dynamics”, Criminology, Vol. 41 No. 4, pp.1173-1206.

Barclays, (2012), Profit or pleasure? Exploring the motivations behind treasure trends. Wealth Insights-Volume 15. 
Binkiewicz, A. (2017), “UK: Police uncover million pound investment scam”, Decanter, 11 August, available at: http://www.decanter.com/wine-news/uk-police-uncover-millionpound-wine-investment-scam-374301/ (accessed 17 August 2017).

Bogner, A., Littig, B. and Menz, W. (2009), Interviewing Experts, Palgrave MacMillan, Basingstoke.

Bosley, S. A., Bellemare, M. F., York, J. and Umwali, L. (2018), "Decision-making and vulnerability in a pyramid scheme fraud", working paper, Hamline University, Minnesota, 1 February.

Braun, V. and Clarke, V. (2006), "Using thematic analysis in psychology", Qualitative Research in Psychology, Vol. 3 No. 2, pp. 77-101.

Budd, J. (2013), "Nouveau world, Finbow wine fraudster imprisoned for seven years", Decanter, 10 September, available at: https://www.decanter.com/wine-news/nouveau-worldfinbow-wine-fraudster-imprisoned-for-seven-years-15820/ (accessed 14 August 2017).

Budd, J. (2015), “Wine fraud: banned director jailed after million pound con”, Decanter, 30 July, available at: https://www.decanter.com/wine-news/wine-fraud-banned-director-jailedafter-million-pound-con-268940/ (accessed 14 August 2017).

Button, M., Lewis, C. and Tapley, J. (2014), "Not a victimless crime: the impact of fraud on individual victims and their families", Security Journal, Vol. 27 No. 1, pp. 36-54. 
Coffman, B. A. and Nance, R. J. (2009), "Wine: The Illiquid Liquid Investment Asset”, Journal of Financial Planning, Vol. 22 No. 12, pp. 1-7.

Crouch, M. and McKenzie, H. (2006), "The logic of small sample sizes in interview-based qualitative research", Social Science Information Trends Report, Vol. 45 No. 4, pp. 483499.

Daab, J. (2011), “The case of the questionable Jeffersonian Lafites: Forensic applications in detecting wine fraud", Journal of Art Crime, Vol. 5, pp. 3-12.

Dimson, E., Marsh. P., \& Staunton, M. (2018). Credit Suissse Global Investment Returns Yearbook 2018: Summary Edition. Credit Suisse AG Research Institute, Zurich. Available online at URL: https://www.creditsuisse.com/corporate/en/articles/media-releases/credit-suisse-globalinvestment-returns-yearbook-2018-201802.html. Last accessed on 6 March 2019.

Dimson, E., Rousseau, P. L. and Spaenjers, C. (2015), “The price of wine”, The Journal of Financial Economics, Vol. 118 No. 2, pp. 431-449.

Drew, J. M. and Cross, C. (2013), "Fraud and its PREY: conceptualising social engineering tactics and its impact on financial literacy outcomes", Journal of Financial Services Marketing, Vol. 18, pp. 188-198. 
Evgenidis, A. and Tsagkanos, A. (2017) "Asymmetric effects on the international transmission of US financial stress. A Threshold VAR approach". International Review of Financial Analysis. Vol 51, No. C, 69-81.

FBI (2018), "Common fraud schemes", The Federal Bureau of Investigation, available at: https://www.fbi.gov/scams-and-safety/common-fraud-schemes (accessed 19 October 2018).

Financial Conduct Authority (2016) "Over 55s at heightened risk of fraud, says FCA", 25 May, available at: https://www.fca.org.uk/news/press-releases/over-55s-heightened-riskfraud-says-fca (accessed 9 August 2017).

Fleming, R. A. (2015), "Protecting elderly investors from financial exploitation: questions to consider", paper presented at The American retirement initiative winter summit, 5 February, Washington DC, available at: https://www.sec.gov/news/speech/protectingelderly-investors-from-financial-exploitation.html (accessed 19 October 2018).

Forward, S. (2015), "Myth: wine investment is safe", Harpers, 28 March, available at: http://www.harpers.co.uk/news/fullstory.php/aid/17322/Myth:_Wine_investment_is_saf e.html (accessed 19 October 2018). 
Frank, R. (2016), "Claims of a Ponzi Scheme in the collapse of a rare-wine seller", The New York Times, 2 April, available at: http://www.nytimes.com/2016/04/03/business/claimsof-a-ponzi-scheme-in-the-collapse-of-a-rare-wine-seller.html (accessed 16 April 2016).

Ganesh, (2016), "What are the preventive and detective controls that can be adopted by investors to avoid wine investment fraud?", working paper, University of Portsmouth, Portsmouth, 9 September.

Graham, W. (2014), “A quantitative analysis of the victims of investment fraud”, working paper, Financial Conduct Authority, London, 15 October, available at: https://www.fca.org.uk/publication/research/quan-study-understanding-victimsinvestment-fraud.pdf (accessed 17 August 2017).

Granovetter, M. (1985), "Economic action and social structure: the problem of embeddedness", American Journal of Sociology, Vol. 91 No. 3, pp. 481-510.

Harvey, S., Kerr, J., Keeble, J. and Nicholls, C. M. (2014), “Understanding victims of financial crime: a qualitative study with people affected by investment fraud", working paper, NatCen Social Research, London, 3 March, available at: https://www.fca.org.uk/publication/research/qual-study-understanding-victimsinvestment-fraud.pdf (accessed 19 October 2018). 
Hines, J. (2001), "Telemarketing fraud upon the elderly: minimizing its effects through legislation, law enforcement and education", Albany Law Journal of Science and Technology, Vol 12, pp. 839-862.

HM Treasury (2017), Over £9.2 billion released by pension freedoms, www.gov.uk 27 January 2017 Available online at https://www.gov.uk/government/news/over-92-billionreleased-by-pension-freedoms Last accessed 7 March 2019.

Holmberg, L. (2010), “Wine fraud”, International Journal of Wine Research, Vol. 2, pp. 105-13.

Kahneman, D. and Tversky, A. (1973), "On the psychology of prediction”, Psychological Review, Vol. 80 No. 4, pp. 237-251.

Langenderfer, J. and Shimp, T. A. (2001), "Consumer vulnerability to scams, swindles, and fraud: A new theory of visceral influences on persuasion", Psychology \& Marketing, Vol. 18 No. 7, pp. 763-783.

Lecat, B., Brouard, J. and Chapuis, C. (2017), "Fraud and counterfeit wines in France: an overview and perspectives", British Food Journal, Vol. 119 No. 1, pp. 84-104.

Levi, M. (2008), “Organized fraud and organizing frauds: unpacking research on networks and organization", Criminology \& Criminal Justice, Vol. 8 No. 4, pp. 389-419. 
Live-Ex (2018) The fine wine market - past, present and future, Available online at https://www.liv-ex.com/2018/09/fine-wine-market-past-present-future/ Last accessed on 7 March 2019.

Lokanan, M. E. (2014), “The demographic profile of victims of investment fraud”, Journal of Financial Crime, Vol. 21 No. 2, pp. 226-242.

Malks, B., Buckmaster, J. and Cunningham, L. (2003), “Combating elder financial abuse - A multi-disciplinary approach to a growing problem”. Journal of Elder Abuse \& Neglect, Vol. 15 No. 3-4, pp. 55-70.

Mannan, T. (2013), “How to spot a wine investment scam”, Your Money, 2 May, available at: http://www.yourmoney.com/investing/how-to-spot-a-wine-investment-scam/ (accessed 15 October 2016).

Marshall, B., Cardon, P., Poddar, A. and Fontenot, R. (2013). Does sample size matter in Qualitative research? A review of qualitative interviews in is research, Journal of Computer Information Systems, Vol. 54 No. 1, pp. 11-22.

Mercer, C. (2015), "Rudy Kurniawan appeals wine fraud conviction”, Decanter, 16 April, available at: https://www.decanter.com/wine-news/rudy-kurniawan-appeals-wine-fraudconviction-915/ (accessed 17 August 2017). 
Mouton, F., Leenen, L., Malan, M. M., and Venter, H. S. (2014). "Towards an ontological model defining the social engineering domain", in $11^{\text {th }}$ IFIP TC9 International conference on human choice and computers, Turku, Finland, 2014, IFIP Advances in information and Communication Technology, pp. 266-279.

Oberschall, A. (2004), "Explaining terrorism: the contribution of collective action theory", Sociological Theory, Vol. 22 No. 1, pp. 26-37.

Olson, M. (1965), The logic of collective action, Harvard University Press, Cambridge.

Ostrom, E. (2009). Building trust to solve commons dilemmas: Taking small steps to test an evolving theory of collective action. In Levin, S.A. (2009) Games, groups, and the global good (pp. 207-228). Springer, Berlin, Heidelberg.

Overton, J., Murray, W. E. and Banks, G. (2012), “The race to the bottom of the glass? Wine, geography, and globalization”, Globalizations, Vol. 9 No. 2, pp. 273-287.

Payne, J. W., Bettman, J. R. and Johnson, E. J. (1988), “Adaptive strategy selection in decision making", Journal of Experimental Psychology Learning, Memory and Cognition, Vol. 14 No. 3, pp. 534-552. 
Pinard, M. (2011), Motivational dimensions in social movements and contentious collective action, McGill-Queen's University Press, Montreal.

Rapp, N. and O'Keefe, B. (2018), The Long-Term Investment That Easily Beats Gold, Art, Stamps, and Wine, Fortune Magazine, April 26, 2018 Available online at http://fortune.com/longform/equities-stock-market-performance/. Last accessed on 6 March 2018.

Robinson, J. and Harding, J. (2015). "Alpha I", in Robinson, J. and Harding, J. (Eds.), The Oxford companion to wine, Oxford University Press, Oxford, pp. 368-388.

Shover, N., Coffey, G. S. and Hobbs, D. (2003), "Crime on the line: Telemarketing and the changing nature of professional crime", The British Journal of Criminology, Vol. 43 No. 3, pp. 489-505.

Simon, H. A. (1990), “Invariants of human behaviour”, Annual Review of Psychology, Vol. 41 No. 1, pp. 1-19.

Stanziani, A. (2004), "Wine reputation and quality controls: the origin of the AOCs in the $19^{\text {th }}$ Century France", European Journal of Law and Economics, Vol. 18 No. 2, pp. 149-167. 
Stevenson, R. J. (1998), The boiler room and other telephone sales scams, University of Illinois Press, USA.

Tsagkanos, A., Evgenidis, A. and Vartholomatou, K. (2018) "Financial and Monetary Stability across Euro-zone and BRICS: An Exogenous Threshold VAR Approach" Research in International Business and Finance, Vol 44 No. C, pp. 386-393.

Tisi, P. (2015), "World wine market in the IWSR report", Vineyard Wine \& Quality, 23 April, available at: http://www.vineyardwineandquality.com/world-wine-market-in-the-iwsrreport/ (accessed 19 October 2018).

Tunley, M. (2011), “Need, greed or opportunity? An examination of who commits benefit fraud and why they do it", Security Journal, Vol. 24 No. 4, pp. 302-319.

Tversky, A. and Kahneman, D. (1973), “Availability: a heuristic for judging frequency and probability", Cognitive Psychology, Vol. 5, pp. 207-232.

United Nations Global Compact (2015), “A practical guide for collective action against corruption”, working paper, United Nations Global Compact, New York, available at: https://www.unglobalcompact.org/docs/issues_doc/AntiCorruption/CollectiveActionExperiencesGlobal.pdf (accessed 17 August 2017). 
Van Bavel, M., Janssens, K., Schakenraad, W. and Thurlings, N. (2010), "Elder abuse in Europe, background and position paper", working paper [01062010], The European Reference Framework Online for the Prevention of Elder Abuse and Neglect, 1 June, available at: http://www.combatingelderabuse.eu/wpcontent/themes/Visionpress/docs/ElderAbuseinEurope.pdf (accessed 19 October 2018).

Van Wyk, J. and Benson, M. L. (1997), "Fraud victimization: risky business or just bad luck?”, American Journal of Criminal Justice, Vol. 21 No. 2, pp. 163-179.

van Zomeren, M., Postmes, T. and Spears, R. (2008), “Toward an integrative social identity model of collective action: a quantitative research synthesis of three socio-psychological perspectives", Psychological Bulletin, Vol. 134 No. 4, pp. 504-535.

Wall, M. (2011), "Beware the fine wine fraudsters having another vintage year". The Independent, 25 June, available at: https://www.independent.co.uk/money/spendsave/beware-the-fine-wine-fraudsters-having-another-vintage-year-2302425.html (accessed 15 August 2017).

Wine Investment Association (2013), "NFIB to combat investment fraud", available at: http://www.wineinvestmentassociation.org/nfib-and-wine-fraud.html (accessed 19 October 2018)

\footnotetext{
${ }^{\mathrm{i}}$ Wine can be categorised as antique after 40-60 years (Dimson et al., 2015).
} 
ii It is important to differentiate between fine wine investment (eg. vintage bottles) and general wine investment. The quality and value is determined by place of origin, (Overton et al., 2012), weather conditions and temperature during grape growth (Stanziani, 2004), and treatment after the wine has been made (Dimson et al., 2015).

iii http://eagle.trea.usc.edu/.

${ }^{\text {iv }}$ http://eagle.trea.usc.edu/types-of-abuse/financial/.

${ }^{\mathrm{v}}$ https://majesticwineplc.co.uk/investor-centre/boiler-room-scams/).

${ }^{v i}$ Although the industry is unregulated, there are self-regulated bodies endorsed by The National Fraud Intelligence Bureau, such as the Wine Investment Association (Wine Investment Association, 2013). 